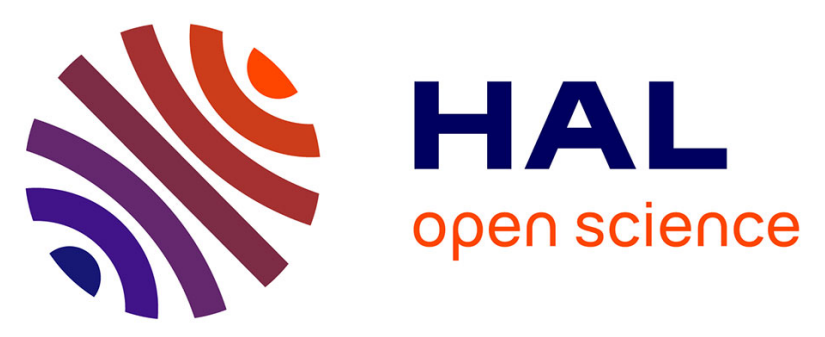

\title{
Analytical magnetic field calculation for flat permanent-magnet linear machines with dual-rotor by using improved two-dimensional hybrid analytical method
}

Brahim Ladghem-Chikouche, Kamel Boughrara, Frédéric Dubas, Rachid

Ibtiouen

\section{To cite this version:}

Brahim Ladghem-Chikouche, Kamel Boughrara, Frédéric Dubas, Rachid Ibtiouen. Analytical magnetic field calculation for flat permanent-magnet linear machines with dual-rotor by using improved two-dimensional hybrid analytical method. COMPEL - The international journal for computation and mathematics in electrical and electronic engineering, 2021, 40 (3), pp.602-623. hal-03359946

\author{
HAL Id: hal-03359946 \\ https://hal.science/hal-03359946
}

Submitted on 30 Sep 2021

HAL is a multi-disciplinary open access archive for the deposit and dissemination of scientific research documents, whether they are published or not. The documents may come from teaching and research institutions in France or abroad, or from public or private research centers.
L'archive ouverte pluridisciplinaire HAL, est destinée au dépôt et à la diffusion de documents scientifiques de niveau recherche, publiés ou non, émanant des établissements d'enseignement et de recherche français ou étrangers, des laboratoires publics ou privés. 


\title{
Analytical Magnetic Field Calculation for Flat Permanent- Magnet Linear Machines with Dual-Rotor by using Improved 2-D Hybrid Analytical Method
}

\author{
B. Ladghem-Chikouche, K. Boughrara, F. Dubas, and R. Ibtiouen
}

\begin{abstract}
Purpose - This paper proposes an improved two-dimensional (2-D) hybrid analytical method (HAM) in Cartesian coordinates, based on the exact subdomain (SD) technique and the magnetic equivalent circuit (MEC).

Design/methodology/approach - The magnetic field solution is obtained by coupling an exact analytical model (AM), calculated in all regions having relative permeability equal to unity, with a MEC, using a nodal-mesh formulation (i.e., Kirchhoff's current law) in ferromagnetic regions. The AM and MEC are connected in both axes $(x, y)$ of the (non-)periodicity direction (i.e., in the interface between the tooth regions and all its adjacent regions as slots and/or air-gap). To provide accuracy solutions, the current density distribution in slot regions is modeled by using Maxwell's equations instead of the MEC characterized by an equivalent magnetomotive force (MMF) located in slots, teeth and yokes.

Findings - It is found that whatever the iron core relative permeability, the developed HAM gives accurate results for noand on-load conditions. Finite-element analysis (FEA) demonstrates excellent results of the developed technique.

Originality/value - The main objective of this paper is to make a direct coupling between the AM and MEC in both directions (i.e., $x$ - and $y$-edges). The current density distribution is modeled by using Maxwell's equations instead of the MEC and characterized by an MMF.
\end{abstract}

Keywords: Hybrid magnetic model, exact subdomain technique, magnetic equivalent circuit, finite-element analysis.

Paper type Research paper

\section{Introduction}

Accurate calculation of the performance for electromagnetic devices based on magnetic field solution is currently of major importance of machine designers. Flat permanent-magnet (PM) linear synchronous machines with dual-rotor presented in this work are one of the many several electromagnetic examples available in the industrial sector. These machines have many advantages over the other machines excited by current.

A wide category of methods is developed for design and optimization to provide an accurate performance information for electrical machines, such as numerical (Matthew and Sadiku, 2011; Niu et al., 2012a and 2012b; Demenko and Sykulski, 2016; Toudji et al., 2017) and (semi-)analytical (Zarko et al., 2006; Boughrara et al., 2009; Sprangers et al., 2015 and 2016; Djelloul-Khedda et al., 2017 and 2018; Ladghem and Ibtiouen, 2020) methods. In the last decades, the exact analytical method (i.e., based on the formal resolution of Maxwell's equations applied in SD) for electrical machines has been very successful (Dubas and Espanet, 2009; Lubin et al., 2010; Boughrara et al., 2013), however, the disadvantage of this method is the infinitely permeable assumption in the iron parts. The advanced AM presented by (Dubas and Boughrara 2017a and 2017b) are one of the great methods that have been made in recent years. This method has been improved by introducing iron core relative permeability in the analytical solution. In (Roubache et al., 2018 and 2019; Ben-Yahia et al., 2018), the authors presented a contribution on the 2 D SD technique based on the principle of superposition in both axes by considering the finite softmagnetic material permeability in spoke-type PM machines and variable flux reluctance machines. Several hybrid magnetic field calculations for electrical machines are proposed, such as the coupling between MEC (i.e., reluctance or permeance network) and: i) FEA (Philips, 1992; Nedjar et al., 2012; Liu et al., 2017), ii) Schwarz-Christoffel method (Hanic et al., 2016 and 2018; Faiz et al., 2019), and iii) analytical model (Laoubi et al., 2015; Ouagued et al., 2016a and 2016b; Bao et al., 2018; Wu et al., 2020). In this paper, the HAM corresponds to a direct coupling between the AM developed by (Dubas and Boughrara 2017a and 2017b) and the 2-D MEC. The MEC presented in (Laoubi et al., 2015; Ouagued et al., 2016a and 2016b; Bao et al., 2018; Wu et al., 2019 and 2020) is relatively simple due to significant simplifications. The coupling between the two models has been investigated for one direction (viz., only in the $x$-axis) and especially in the interface between the air-gap and the stator core. In these references, 


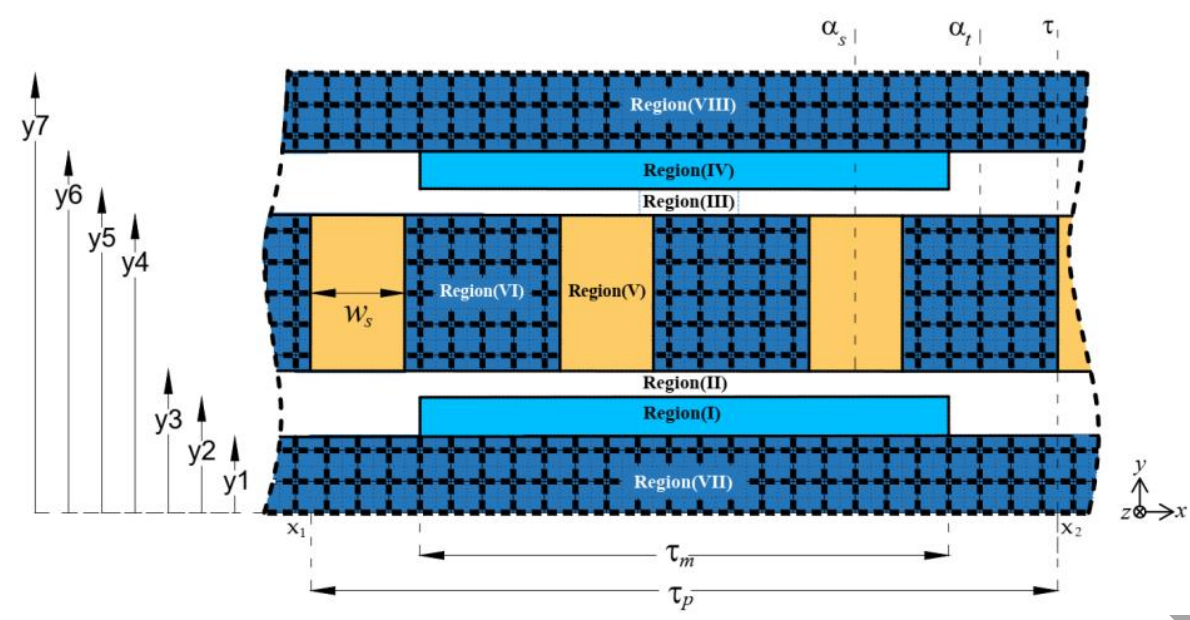

Fig. 1. Proposed flat linear PM synchronous machine.

the stator topology is assumed to be current-free and only PM can be assumed as sources. For these conditions, the current density in slot regions is not incorporated in the equation system to be solved, because the equations governed in these regions are based on a nodal-based formulation (i.e., Kirchhoff's current law) described by a scalar potential distribution. The current density has been replaced by an equivalent MMF source (Ouagued et al., 2016b; Bao et al., 2018) or by equivalent current sheets (Wu et al., 2019 and 2020) where good results are obtained compared to FEA.

In this work, a 2-D HAM improves the coupling problem of the two models in both directions (i.e., $\mathrm{x}$ and y-edges). In this case, and to give a more accurate result than that presented by (Laoubi et al., 2015; Ouagued et al., 2016a and 2016b; Bao et al., 2018; Wu et al., 2019 and 2020), HAM proposed is based on the: i) exact AM based on the formal resolution of Maxwell's equations applied in all regions at unitary relative permeability (viz., the air-gap, slots and PMs), and ii) MEC using a nodal-mesh formulation applied to the other ferromagnetic regions (viz., teeth, and rotor/stator yoke). Moreover, the 2-D MEC is characterized by an equivalent MMF located in the slots, teeth and yokes. An accurate magnetic flux distribution can be easily calculated in all SDs by including the current density in the equations system.

\section{Model Definition and Assumptions}

The flat PM linear synchronous machine with rotor-dual, shown in Fig. 1, is composed to eight orthogonal subdomains as follows:

1) PMs: Region I and IV;

2) Vacuum: Region H and III;

3) $Q$ slots with coils: Region $\mathrm{V}$ with the index $x=1 . . Q$;

4) $Q$ soft-material: Region VI with the index $x=1 . . Q$;

5) Iron yoke: Region VII and VIII.

The rotor topology consists of PMs with radial array fixed to the surface. The stator topology consists of slots with radial sides surface. Three-phases winding arranged in the slots is configured in a standard (i.e., non-overlapping or concentrated winding) with a single-layer.

In this paper, the proposed machine is described on a 2-D cartesian coordinate system. The magnetic field solution can be obtained under the following assumptions:

1) the problem is quasi-static;

2) the longitudinal end-effects and transverse edge-effects are neglected;

3) the stator tooth-tips are not considered. However, they can be introduced easily;

4) all regions have radial sides;

5) the magnetic vector potential in all regions has only one component along the $z$-axis, i.e., $\boldsymbol{A}=$ $\left\{0 ; 0 ; A_{z}\right\}$; 
6) the current density in the stator slots has only one component along the $z$-axis, i.e., $\boldsymbol{J}=$ $\left\{0 ; 0 ; J_{z}\right\}$

7) the electrical conductivity in all regions is assumed to be zero (i.e., there are no eddy-current losses in the PMs or armature windings);

8) all regions are considered as isotropic;

9) the PMs are considered to have a linear second quadrant characteristic and the PMs absolute permeability is assumed to be equal to that of vacuum, viz., $\mu_{m} \cong \mu_{o}$.

\section{Formulation of HAM}

\section{A. Introduction}

In this paper, a 2-D HAM based on the SD technique and MEC is presented. Each SD of the proposed machine is modeled under a constant relative permeability $\mu=C^{s t}$ and expressed either by: i) a partial differential equation (PDE) in terms of $\boldsymbol{A}$, or ii) the Kirchhoff's laws governed by magnetic vector scalar $\mathrm{u}$.

$\boldsymbol{A}$ and u can be defined respectively as

$$
\begin{gathered}
\nabla^{2} \boldsymbol{A}=-\left[\mu \boldsymbol{J}+\mu_{0} \nabla \times \boldsymbol{M r}\right] \\
\boldsymbol{H}=-\nabla u
\end{gathered}
$$

where $\boldsymbol{J}$ is the current density (due to supply currents) vector, $\boldsymbol{M r}$ is the remanent magnetization vector (with $\boldsymbol{M r}=0$ for the vacuum/iron or $\boldsymbol{M r} \neq 0$ for the PMs according to the magnetization direction), and $\mu=\mu_{0} \cdot \mu_{r}$ is the absolute magnetic permeability of the magnetic material in which $\mu_{0}$ and $\mu_{r}$ are respectively the vacuum permeability and the relative permeability of magnetic material (with $\mu_{r}=1$ for the vacuum or $\mu_{r} \neq 1$ for the PMs/iron).

\section{B. 2-D Exact SD Technique}

The PDE for magnetic field in Region I, II, III, IV and V can be written as

$$
\begin{array}{ll}
\nabla^{2} \boldsymbol{A}=-\mu_{o} \nabla \times \boldsymbol{M r} & \text { in Regions I and IV } \\
\nabla^{2} \boldsymbol{A}=0 & \text { in Regions II and III } \\
\nabla^{2} \boldsymbol{A}=-\mu_{0} \boldsymbol{J} & \text { in Region V }
\end{array}
$$

The magnetization vector $\boldsymbol{M} \boldsymbol{r}$ of PMs can be expressed by

$$
M \boldsymbol{r}=M r_{x} \boldsymbol{x}+M r_{y} \boldsymbol{y}
$$

where $M r_{x}$ and $M r_{y}$ are respectively the x- and y-component of $\boldsymbol{M r}$. The proposed electrical machine has anti-periodicity equal to $\tau_{p}=\pi / p$ with $p$ is the number of pole pairs. The components of $\boldsymbol{M r}$ can be described explicitly by Fourier's series as

$$
\begin{aligned}
& M r_{x}=\sum_{n}\left[M r_{x s n} \cdot \sin \left(K_{n} x\right)+M r_{x c n} \cdot \cos \left(K_{n} x\right)\right] \\
& M r_{y}=\sum_{n}\left[M r_{y s n} \cdot \sin \left(K_{n} x\right)+M r_{y c n} \cdot \cos \left(K_{n} x\right)\right]
\end{aligned}
$$

where $K_{n}=n \pi / \tau_{p}$ with $n$ is the spatial harmonic order. The expressions of $M r_{x s n}, M r_{x c n}, M r_{y s n}$ and $M r_{y c n}$ are detailed in Appendix A.

The field vectors $\boldsymbol{B}=\left\{B_{x} ; B_{y} ; 0\right\}$ and $\boldsymbol{H}=\left\{H_{x} ; H_{y} ; 0\right\}$ are coupled by the magnetic material equation

$$
\begin{array}{cc}
\boldsymbol{B}=\mu_{m} \boldsymbol{H}+\mu_{o} \boldsymbol{M r}=\mu_{o}(\boldsymbol{H}+\boldsymbol{M r}) & \text { in Region I and IV } \\
\boldsymbol{B}=\mu_{0} \boldsymbol{H} & \text { in other regions }
\end{array}
$$


Using $\boldsymbol{B}=\nabla \times \boldsymbol{A}$, the components of $\boldsymbol{B}$ can be deduced by

$$
B_{x}=\frac{\partial A_{z}}{\partial y} \quad \& \quad B_{y}=-\frac{\partial A_{z}}{\partial x}
$$

In Cartesian coordinates $(x, y),(3)$ in terms of $\boldsymbol{A}=\left\{0 ; 0 ; A_{z}\right\}$ can be rewritten as

- in Region I and IV (i.e., Poisson's equation):

$$
\frac{\partial^{2} A_{z}^{I, I V}}{\partial x^{2}}+\frac{\partial^{2} A_{z}^{I, I V}}{\partial y^{2}}=-\mu_{o} \cdot\left(\frac{\partial M r_{y}}{\partial x}-\frac{\partial M r_{x}}{\partial y}\right)
$$

- in Region II and III (i.e., Laplace's equation):

$$
\frac{\partial^{2} A_{z}^{I I, I I I}}{\partial x^{2}}+\frac{\partial^{2} A_{z}^{I I, I I I}}{\partial y^{2}}=0
$$

- $\quad$ in Region V (i.e., Poisson's equation):

$$
\frac{\partial^{2} A_{z}^{V}}{\partial x^{2}}+\frac{\partial^{2} A_{z}^{V}}{\partial y^{2}}=-\mu_{0} \cdot J_{z}
$$

The PDEs (8) (10) can be solved by using the separation of variables method and the Dubas' superposition technique. All regions of the proposed machine are described by Fourier series expression in both directions (i.e., $\mathrm{x}$ - and y-edges).

The general solution of $A_{z}$, which is the superposition of two components in x- and y-directions (Dubas and Boughrara, 2017a), can be described as:

- in Region I and IV:

$$
A_{z}^{I, I V}=\sum_{n}\left(\begin{array}{c}
C_{3 n}^{I, I V} \cdot e^{K_{n} y} \\
\cdots+C_{4 n}^{I, I V} \cdot e^{-K_{n} y}+\Gamma_{s}
\end{array}\right) \cdot \sin \left(K_{n} x\right)+\sum_{n}\left(\begin{array}{c}
C_{5 n}^{I, I V} \cdot e^{K_{n} y} \\
\cdots+C_{6 n}^{I, I V} \cdot e^{-K_{n} y}+\Gamma_{c}
\end{array}\right) \cdot \cos \left(K_{n} x\right)
$$

where

$$
\Gamma_{s}=-\mu_{o} \cdot \frac{M r_{y c n}}{K_{n}} \quad \& \quad \Gamma_{c}=\mu_{o} \cdot \frac{M r_{y s n}}{K_{n}}
$$

- $\quad$ in Region II and III:

$$
A_{z}^{I I, I I I}=\sum_{n}\left(\begin{array}{c}
C_{3 n}^{I I, I I I} \cdot e^{K_{n} y} \\
\cdots+C_{4 n}^{I L, H I} \cdot e^{-K_{n} y}
\end{array}\right) \cdot \sin \left(K_{n} x\right)+\sum_{n}\left(\begin{array}{c}
C_{5 n}^{I I, I I I} \cdot e^{K_{n} y} \\
\cdots+C_{6 n}^{I I, I I I} \cdot e^{-K_{n} y}
\end{array}\right) \cdot \cos \left(K_{n} x\right)
$$

- in Region V:

$$
\begin{gathered}
A_{z s}^{V}=C_{s 1}^{V}+C_{s 2}^{V} \cdot y-\frac{1}{2} \cdot \mu_{o} \cdot J_{z s} \cdot y^{2} \\
\ldots+\sum_{m} G_{s m}^{V x} \cdot \cos \left[\beta_{m}^{V} \cdot\left(x-\alpha_{s}+\frac{w_{s}}{2}\right)\right]+\sum_{v} G_{s v}^{V y} \cdot \sin \left[\lambda_{v}^{V} \cdot\left(y-y_{3}\right)\right] \\
G_{s m}^{V x}=C_{s 3 m}^{V} \cdot e^{\beta_{m}^{V} y}+C_{s 4 m}^{V} \cdot e^{-\beta_{m}^{V} y} \\
G_{s v}^{V y}=C_{s 5 v}^{V} \cdot \sinh \left[\lambda_{v}^{V} \cdot\left(x-\alpha_{s}+\frac{w_{s}}{2}\right)\right]+C_{s 6 v}^{V} \cdot \sinh \left[\lambda_{v}^{V} \cdot\left(x-\alpha_{s}-\frac{w_{s}}{2}\right)\right]
\end{gathered}
$$

with

$$
J_{z s}=J_{m} \cdot\left[\begin{array}{lllllllllllll}
1 & 1 & 0 & -1 & -1 & 0 & 1 & 1 & 0 & -1 & -1 & 0
\end{array}\right]
$$

where $J_{m}$ is the current density peak, $\alpha_{s}$ is the position of $\mathrm{s}^{\text {th }}$ slot, $m$ and $v$ are the spatial harmonic orders, 
$\beta_{m}^{V}$ and $\lambda_{v}^{V}$ are the spatial frequency (or periodicity) in both directions defined by

with $w_{s}$ is the slot-opening.

$$
\beta_{m}^{V}=\frac{m \pi}{w_{s}} \quad \& \quad \lambda_{v}^{V}=\frac{v \pi}{\mathrm{y}_{4}-\mathrm{y}_{3}}
$$

\section{2-D MEC (viz., Reluctance or Permeance Network)}

In Region VI, VII and VIII, the solution of magnetic scalar potential distribution $u$ can be obtained from Kirchhoff's laws. From Fig. 2, the magnetic flux can be written as follows:

$$
\begin{gathered}
\sum_{j=a, b, c, d} \varphi_{s, i j}=0 \\
u_{s, i}-u_{s, j}=\frac{\varphi_{s, i j}}{P_{s, i j}}
\end{gathered}
$$

and then,

$$
\begin{gathered}
u_{s, i} \cdot \sum_{j=a, b, c, d} P_{s, i j}-\sum_{j=a, b, c, d}\left(P_{s, i j} \cdot u_{s, j}\right)=0 \\
P_{s, i j}=\frac{1}{\Re_{s, i j}}=\mu_{0} \cdot \mu_{r} \cdot \frac{\delta_{s, i j}}{L}
\end{gathered}
$$

where $L$ and $\delta_{s, i j}$ are respectively the active length and section of the reluctance element $\Re$.

Using (2), the components of $\boldsymbol{H}$ can be deduced by

$$
H_{x}=-\frac{\partial u}{\partial x} \quad \& \quad H_{y}=-\frac{\partial u}{\partial y}
$$

Fig. 2. 2-D reluctance elements $\Re$, magnetic scalar potential $u$ and magnetic flux $\varphi$.

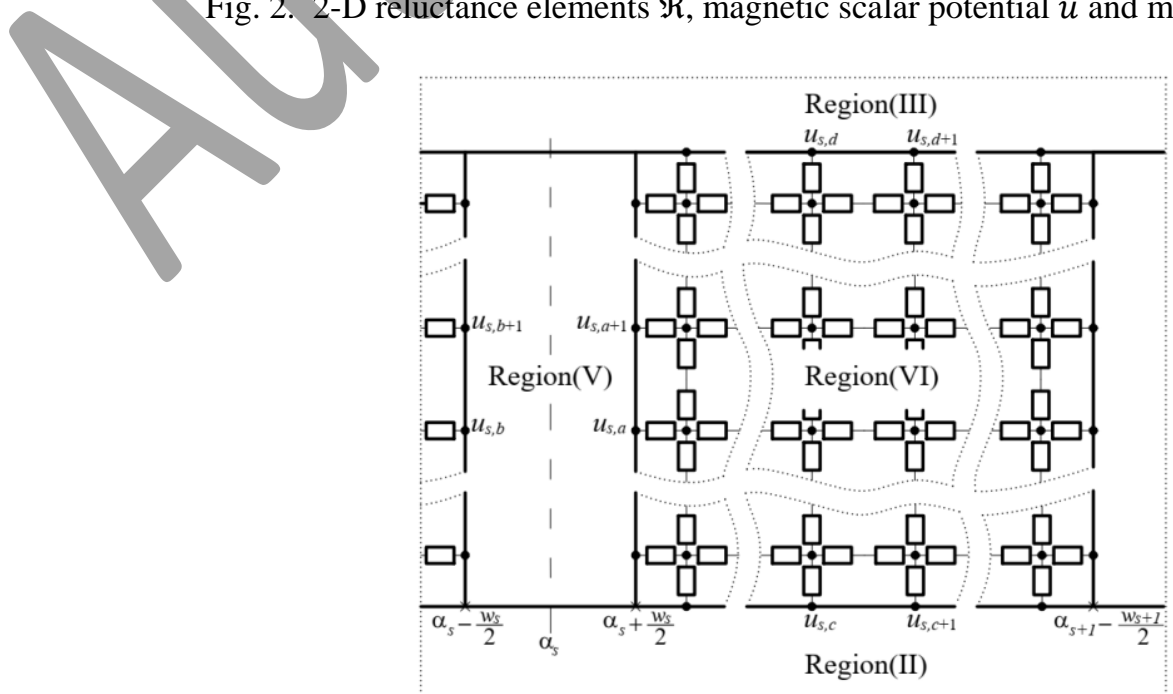

Fig. 3. Uniform mesh of the Region VI discretized into several BD blocks. 
Since (20) are applicable for the analytical solutions of Maxwell's equations. These equations must be rewritten using numerical differentiation defined as the limit of a difference quotient as:

$$
H_{x}(x)=\lim _{\Delta x \rightarrow 0}\left(-\frac{\Delta u}{\Delta x}\right) \quad \& \quad H_{y}(y)=\lim _{\Delta y \rightarrow 0}\left(-\frac{\Delta u}{\Delta y}\right)
$$

The difference quotient $H_{x}(x)$ and $H_{y}(y)$ is a derivative approximation. This improves as $\Delta \mathrm{x}$ and $\Delta \mathrm{y}$ become smaller.

\section{Boundary Conditions and Linear System}

To give the final solution of equations system, the boundary conditions (BCs) must be defined by equalizing the magnetic potential vector $A_{z}$, the $y$-component of $\boldsymbol{B}$ and the $x$-component of $\boldsymbol{H}$ in all BCs.

On the $x$-direction:

- At $y=y_{1}$ and $\forall x$ :

$$
\begin{gathered}
P_{i d} \cdot\left(u_{i}-u_{d}\right)=L \cdot \int_{x_{j}}^{x_{j}+\Delta \mathrm{x}} B_{y}^{I}\left(x, y_{1}\right) d x \\
H_{x}^{V I I}\left(x, y_{1}\right)=H_{x}^{I}\left(x, y_{1}\right)
\end{gathered}
$$

In order to satisfy (23), the magnetic flux intensity $H_{x}^{V I I}\left(x, y_{1}\right)$ by applying (21) should be written as:

$$
H_{x s}^{V I I}\left(x, y_{1}\right)=-\sum_{c=1}^{N C-1} \sum_{v}\left(\frac{u_{c+1}-u_{c}}{\Delta x}\right) \cdot\left[h_{x s v}^{V I I} \cdot \sin \left(K_{n} x\right)+h_{x c v}^{V I I} \cdot \cos \left(K_{n} x\right)\right]
$$

where $N C$ is the number of reluctance rows in Region VII as well as the Region VI and VIII, and $h_{x s v}^{V I I} \&$ $h_{x c v}^{V I I}$ are the Fourier's constants.

- At $y=y_{2}$ and $\forall x$ :

$$
\begin{aligned}
& A_{z}^{I}\left(x, y_{2}\right)=A_{z}^{I I}\left(x, y_{2}\right) \\
& H_{x}^{I}\left(x, y_{2}\right)=H_{x}^{I I}\left(x, y_{2}\right)
\end{aligned}
$$

- At $y=y_{3}$ and $\forall x$ :

$$
\begin{aligned}
& P_{s, c i} \cdot\left(u_{s, c}-u_{s, i}\right)=L \cdot \int_{x_{s, j}}^{x_{s, j}+\Delta \mathrm{x}} B_{y}^{I I}\left(x, y_{3}\right) d x \\
& \left.\left\{A_{z}^{I I}\left(x, y_{3}\right)=A_{z S}^{V}\left(x, y_{3}\right)\right\}\right|^{\alpha_{S}-\frac{w_{S}}{2} \leq x \leq \alpha_{S}+\frac{w_{S}}{2}} \\
& H_{x}^{I I}\left(x, y_{3}\right)=\sum_{S=1}^{Q}\left(\left.H_{x S}^{V}\left(x, y_{3}\right)\right|^{\alpha_{S}-\frac{w_{S}}{2} \leq x \leq \alpha_{S}+\frac{w_{S}}{2}}+\left.H_{x S}^{V I}\left(x, y_{3}\right)\right|^{\alpha_{S}+\frac{w_{S}}{2} \leq x \leq \alpha_{S+1}-\frac{w_{S}+1}{2}}\right)
\end{aligned}
$$

where $Q$ is the number of regular distribution under a pole-pitch.

In order to satisfy (29), the magnetic flux intensity $H_{x S}^{V I}\left(x, y_{3}\right)$ by applying (21) should be written as:

$$
H_{x S}^{V I}\left(x, y_{3}\right)=-\sum_{c=1}^{N C-1} \sum_{v}\left(\frac{u_{s, c+1}-u_{s, c}}{\Delta x}\right) \cdot\left[h_{x s v}^{V I} \cdot \sin \left(K_{n} x\right)+h_{x c v}^{V I} \cdot \cos \left(K_{n} x\right)\right]
$$

where $h_{x s v}^{V I} \& h_{x c v}^{V I}$ are the Fourier's constants. 
- At $y=y_{4}$ and $\forall x$ :

$$
\begin{aligned}
& P_{s, i d} \cdot\left(u_{s, i}-u_{s, d}\right)=L \cdot \int_{x_{s, j}}^{x_{s, j}+\Delta x} B_{y}^{I I I}\left(x, y_{4}\right) d x \\
& \left.\left\{A_{z}^{I I I}\left(x, y_{4}\right)=A_{z S}^{V}\left(x, y_{4}\right)\right\}\right|^{\alpha_{S}-\frac{w_{S}}{2} \leq x \leq \alpha_{S}+\frac{w_{S}}{2}} \\
& H_{x}^{I I I}\left(x, y_{4}\right)=\sum_{x=1}^{Q}\left(\left.H_{x S}^{V}\left(x, y_{4}\right)\right|^{\alpha_{S}-\frac{w_{S}}{2} \leq x \leq \alpha_{S}+\frac{w_{S}}{2}}+\left.H_{x S}^{V I}\left(x, y_{4}\right)\right|^{\alpha_{S}+\frac{w_{S}}{2} \leq x \leq \alpha_{S+1}-\frac{w_{S}+1}{2}}\right)
\end{aligned}
$$

where

$$
H_{x S}^{V I}\left(x, y_{4}\right)=-\sum_{d=1}^{N C-1} \sum_{v}\left(\frac{u_{s, d+1}-u_{s, d}}{\Delta x}\right) \cdot\left[h_{x s v}^{V I} \cdot \sin \left(K_{n} x\right)+h_{x c v}^{V I} \cdot \cos \left(K_{n} x\right)\right]
$$

- At $y=y_{5}$ and $\forall x$ :

$$
\begin{aligned}
& A_{z}^{I I I}\left(x, y_{5}\right)=A_{z}^{I V}\left(x, y_{5}\right) \\
& H_{x}^{I I I}\left(x, y_{5}\right)=H_{x}^{I V}\left(x, y_{5}\right)
\end{aligned}
$$

- At $y=y_{6}$ and $\forall x$ :

$$
\begin{gathered}
P_{c i} \cdot\left(u_{c}-u_{i}\right)=L \cdot \int_{x_{j}}^{x_{j}+\Delta \mathrm{x}} B_{y}^{V I I I}\left(x, y_{6}\right) d x \\
H_{x}^{I V}\left(x, y_{6}\right)=H_{x}^{V I I I}\left(x, y_{6}\right)
\end{gathered}
$$

The magnetic flux intensity $H_{x}^{V I I I}\left(x, y_{6}\right)$ by applying (21) should be written as

$$
H_{x S}^{V I I I}(x, \mathrm{y})=-\sum_{c=1}^{N C-1} \sum_{v}\left(\frac{u_{c+1}-u_{c}}{\Delta x}\right) \cdot\left[h_{x s v}^{V I I I} \cdot \sin \left(K_{n} x\right)+h_{x c v}^{V I I I} \cdot \cos \left(K_{n} x\right)\right]
$$

where $h_{x S v}^{V I I I} \& h_{x c v}^{V I I I}$ are the Fourier's constants.

On the $y$-direction, viz., on the edges of the Region V and the Region VI:

- For $x=\alpha_{s}+w_{s} / 2$ and $\forall y$ :

$$
\begin{gathered}
P_{s, a i} \cdot\left(u_{s, a}-u_{s, i}\right)=L \cdot \int_{y_{k}}^{y_{k}+\Delta y} B_{x s}^{V}\left(\alpha_{s}+\frac{w_{s}}{2}, y\right) d y \\
H_{y s}^{V}\left(\alpha_{s}+\frac{w_{s}}{2}, y\right)=H_{y s}^{V I}(y)
\end{gathered}
$$

In order to satisfy (41), the magnetic flux density $H_{y s}^{V I}(y)$ by applying (21) should be written

$$
H_{y s}^{V I}(y)=-\sum_{a=1}^{N L-1} \sum_{v}\left(\frac{u_{s, a+1}-u_{s, a}}{\Delta y}\right) \cdot h_{y s v}^{V I} \cdot \sin \left[\lambda \cdot\left(y-y_{2}\right)\right]
$$

where $N L$ is the number of reluctance columns, and $h_{y s v}^{V I}$ is Fourier's constant.

- For $x=\alpha_{s}-w_{s} / 2$ and $\forall y$ :

$$
\begin{gathered}
P_{s-1, i b} \cdot\left(u_{s-1, i}-u_{s-1, b}\right)=L \cdot \int_{y_{k}}^{y_{k}+\Delta y} B_{x s}^{V}\left(\alpha_{s}-\frac{w_{s}}{2}, y\right) d y \\
H_{y s}^{V}\left(\alpha_{s}-\frac{w_{s}}{2}, y\right)=H_{y(s-1)}^{V I}(y)
\end{gathered}
$$




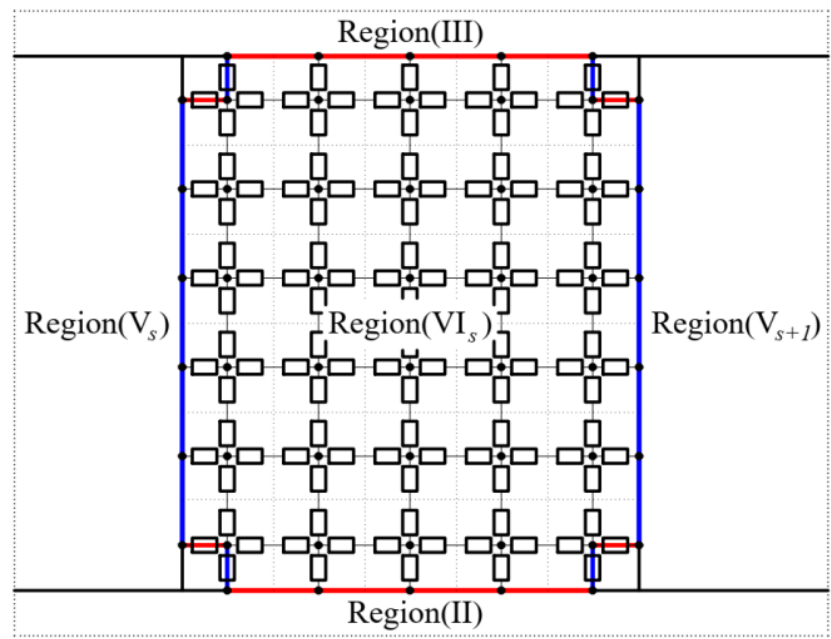

Fig. 4. Proposed BCs between Region VI and V (blue color), and Region VI and Regions II \& III (red color).

Again, to satisfy (44), the magnetic flux intensity $H_{y s}^{V I}(\mathrm{y})$ in the left side of Region $\mathrm{V}$ must be written as (42) by changing the variable $a$ by $b$ [see Fig. 3].

For simplicity, the proposed machine can be modeled for half of the period. For this case, anti-periodic BCs are proposed at $x=x_{1}$ and $x=x_{2}$ [see Fig. 1]:

$$
\begin{gathered}
P_{Q, i b} \cdot\left(u_{Q, i}-u_{Q, b}\right)=-L \cdot \int_{y_{k}}^{y_{k}+\Delta y} B_{x 1}^{V}\left(\alpha_{1}-\frac{w_{1}}{2}, y\right) d y \\
H_{y 1}^{V}\left(\alpha_{1}-\frac{w_{1}}{2}, y\right)=-H_{y Q}^{V I}(y)
\end{gathered}
$$

Fig. 4 shows a regular discretization of Region VI. Since there are no nodes in the corners in this region, a direct coupling between both models is done by respecting the interface indicated by blue and red color.

It can be seen that all BCs are defined and the correlation of Fourier's constants can be found as detailed in Appendix B. Thus, the system of linear algebraic equations can be written as follows:

$$
[A] \cdot[X]=[b]
$$

where $[A](N \times N)$ is the topological matrix, $[b](N \times 1)$ is the vector contain all flux source parameters, and $[X](N \times 1)$ is the vector contain all the indeterminate Fourier coefficients.

\section{Analysis Results}

The parameters of the proposed electrical machine are shown in Table I. Figs. $5 \sim 8$ show a comparison between HAM and FEA for the open-circuit [see Figs. 5 6] and armature reaction [see Figs. $7 \sim 8$ ] magnetic flux density distribution with a radial magnetization pattern in the middle of Region II (i.e., in the vacuum) with different values of iron core relative permeability (viz., $\mu_{r}=2$ and 1,000). The maximal current density is equal to $J_{m}$ [see Table I]. These results have been calculated with acceptable discretization of Region VI $(N C=31$ and $N L=15)$ and Regions VII \& VIII $(N C=45$ and $N L=15)$. Excellent agreement is obtained between the two models.

Figs. $9 \sim 10$ show respectively the magnetic flux density distribution in the middle of the three slots and teeth under open-circuit [see Fig. 9] and armature reaction [see Fig. 10] conditions with different relative permeability values of stator core (viz., $\mu_{r}=2$ and 1,000). To avoid computational errors, the mesh discretization in teeth regions should be chosen fine $(N C=51$ and $N L=51)$ unlike to the previous case where $N C=31$ and $N L=15$. An excellent agreement is achieved between HAM and FEA whatever the relative permeability values. The computational time is increased to approximately 4 times. 
COMPEL: The International Journal for Computation and Mathematics in Electrical and Electronic Engineering DOI: 10.1108/COMPEL-02-2021-0039
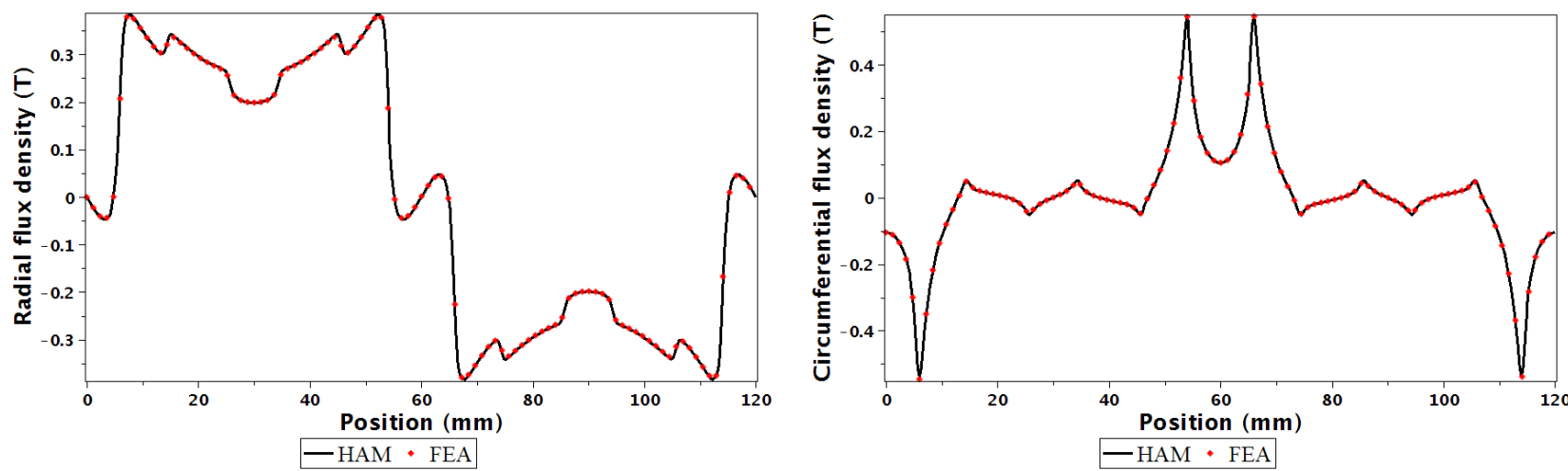

Fig. 5. Comparison of HAM and FEA predicted for the open-circuit magnetic flux density distribution with a radial magnetization pattern in the middle of the Region II for $\mu_{r}=2$ in all ferromagnetic regions.
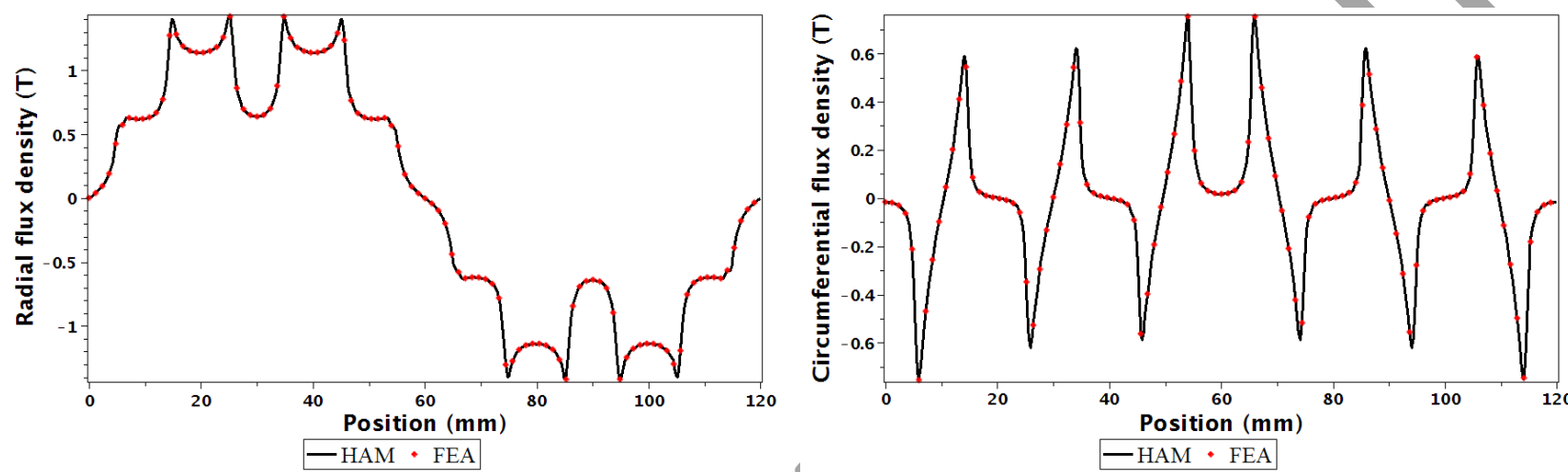

Fig. 6. Comparison of HAM and FEA predicted for the open-circuit magnetic flux density distribution with a radial magnetization pattern in the middle of Region II for $\mu_{r}=1,000$ in all ferromagnetic regions.
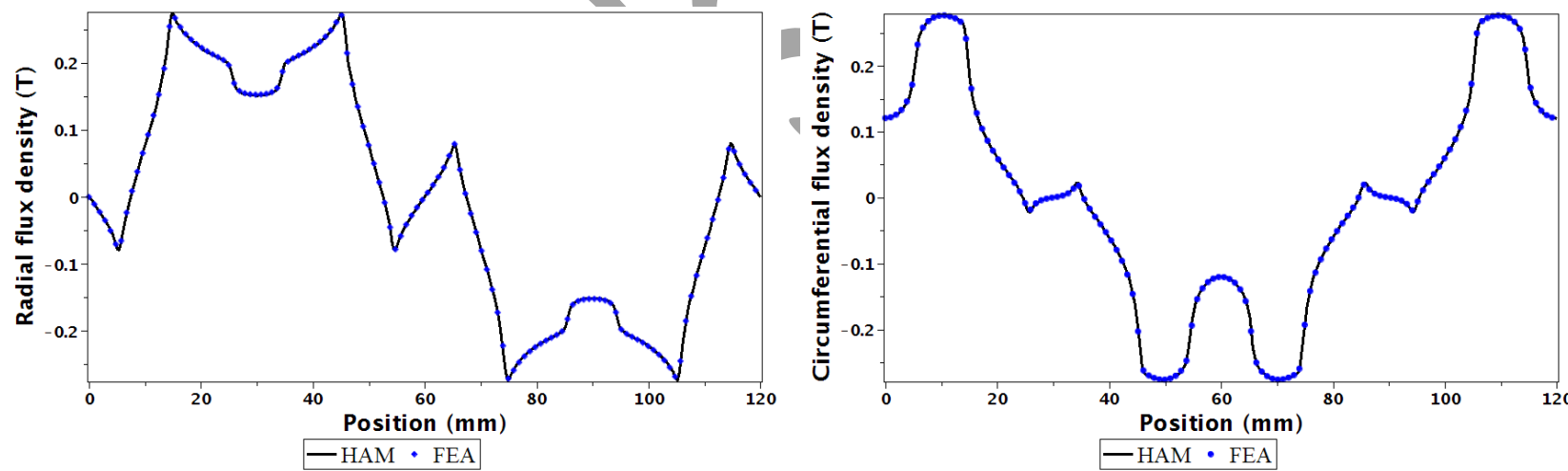

Fig. 7. Comparison of HAM and FEA predicted of the armature reaction magnetic flux density in the middle of Region II for $\mu_{r}=2$ in all ferromagnetic regions.
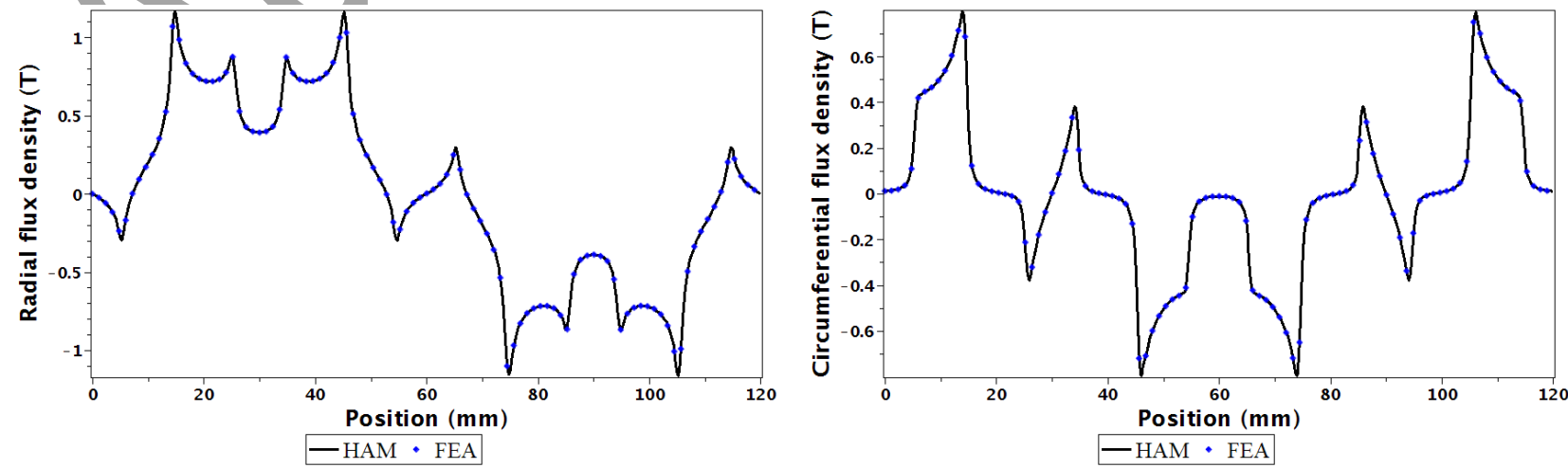

Fig. 8. Comparison of HAM and FEA predicted of the armature reaction magnetic flux density in the middle of Region II for $\mu_{r}=1,000$ in all ferromagnetic regions. 
COMPEL: The International Journal for Computation and Mathematics in Electrical and Electronic Engineering DOI: 10.1108/COMPEL-02-2021-0039
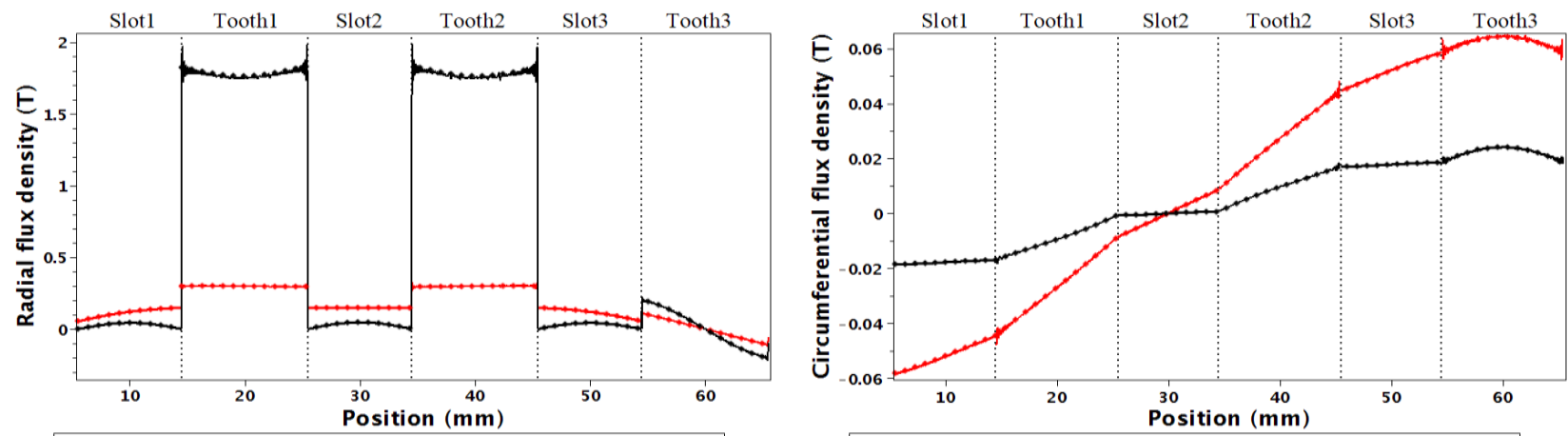

$-\operatorname{HAM}(u=2)+\mathrm{FEA}(\mathrm{ur}=2)-\operatorname{HAM}(\mathrm{u}=1000)+\mathrm{FEA}(\mathrm{ur}=1000)$

$-\operatorname{HAM}(\mathrm{ur}=2)+\mathrm{FEA}(\mathrm{ur}=2)-\mathrm{HAM}(\mathrm{u}=1000)+\mathrm{FEA}(\mathrm{ur}=1000)$

Fig. 9. Comparison of HAM and FEA predicted for the open-circuit magnetic flux density distribution with a radial magnetization pattern in the middle of Region V and VI.
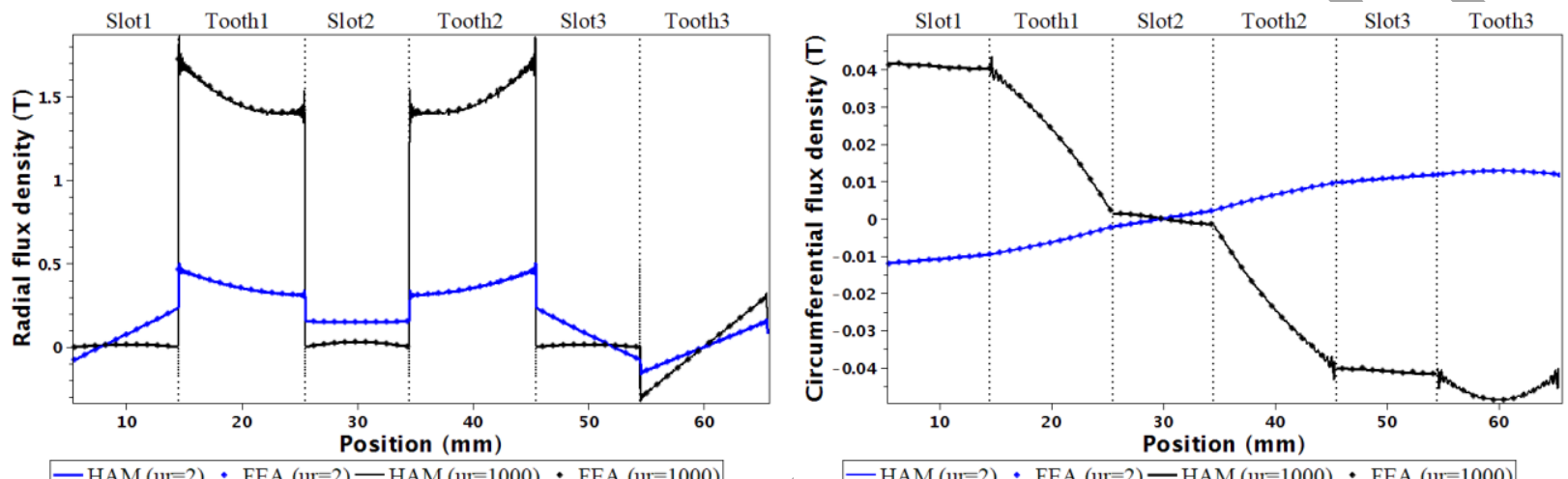

- HAM (ur=2) - FEA (ur=2) - HAM (ur=1000) $\cdot$ FEA (ur=1000)

- HAM (ur=2) - FEA (ur=2) - HAM (ur=1000) $\cdot$ FEA (ur=1000)

Fig. 10. Comparison of HAM and FEA predicted of the armature reaction magnetic flux density distribution in the middle of Region V and VI.

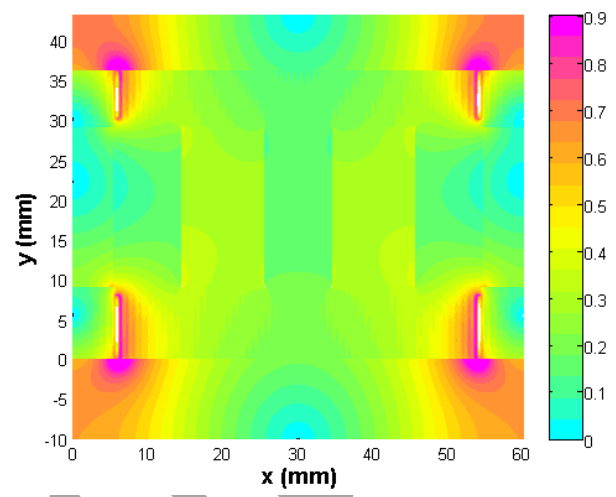

HAM

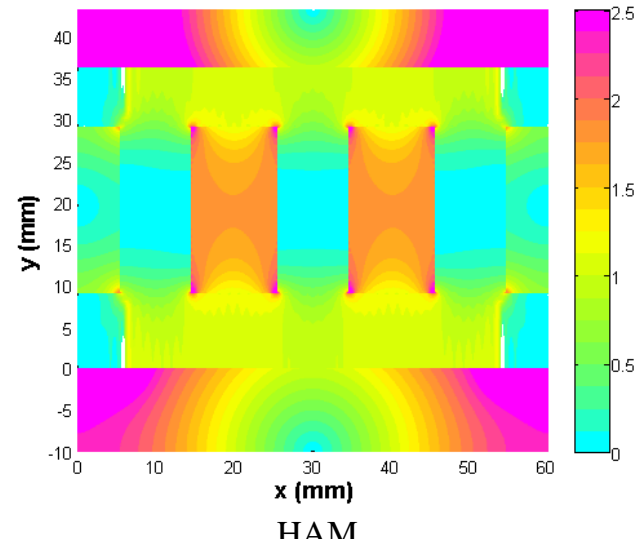

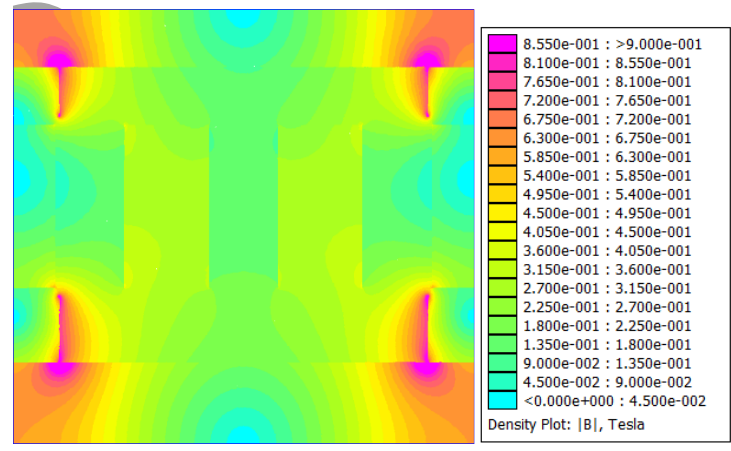

FEA

(a)

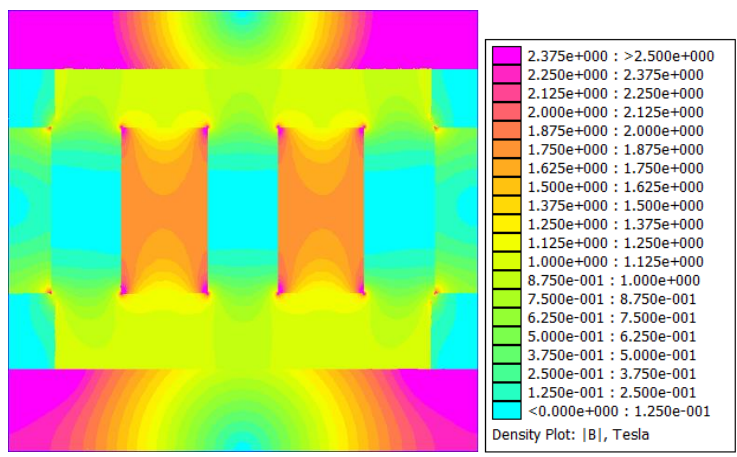

FEA

(b)

Fig. 11. Magnetic flux density $\|\boldsymbol{B}\|$ distribution calculated by HAM and FEA under no-load condition for: (a) $\mu_{r}=2$ and (b) $\mu_{r}=1,000$. 

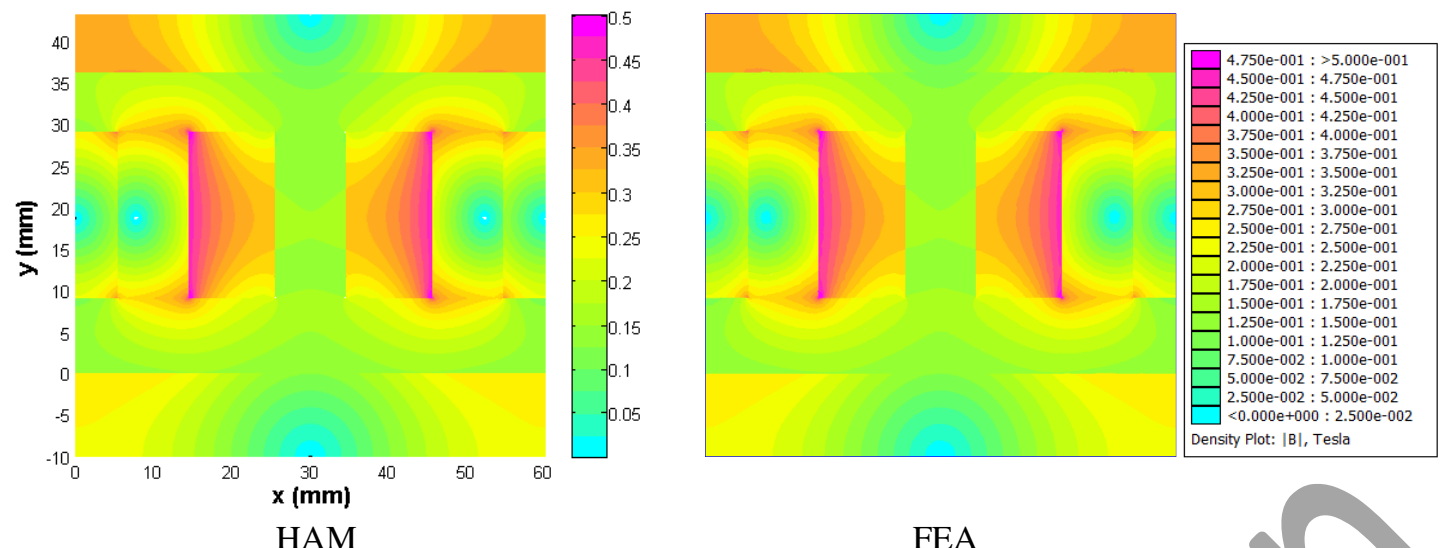

(a)

FEA
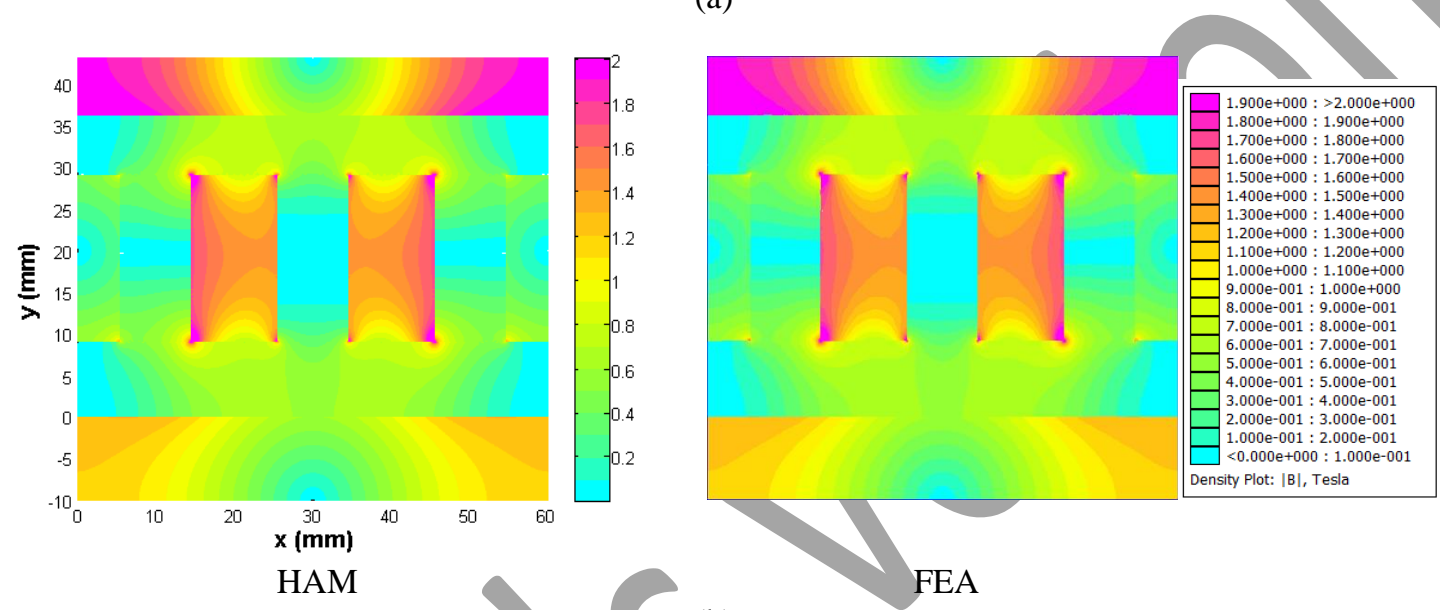

(b)

Fig. 12. Magnetic flux density $\|\boldsymbol{B}\|$ distribution calculated by HAM and FEA under armature reaction current condition for: (a) $\mu_{r}=2$ and (b) $\mu_{r}=1,000$.

Table II shows the time consuming required to calculate the magnetic flux density by different approaches such as HAM, SD technique and FEA. For the SD technique, the HAM in teeth regions and rotor yoke are replaced by AM as indicated in (Ben-Yahia et al., 2018; Roubache et al., 2019).

Figs. $11 \sim 12$ show the magnetic flux density distribution in all parts of electrical machine calculated by HAM and compared to FEA with different values of iron core relative permeability.

\section{Conclusion}

In this paper, a 2-D HAM in Cartesian coordinates has been proposed for the flat PM linear synchronous machines with rotor-dual and a radial magnetization pattern of PMs. The developed model is based on the exact AM by applying Dubas' superposition technique able to be coupled to MEC in both directions (i.e., $x$ - and $y$-edges). The excitation currents of winding have been represented by current density in slots contrary to the previous case where MMF based on Kirchhoff's law is used. Excellent accuracy results are presented and compared with those obtained by FEA for any value of iron core relative permeability. Whatever the operating conditions, this approach can greatly help to precisely optimize the performances of the electrical machine, in particular with the local saturation effect that will be proposed in a future contribution.

\section{REFERENCES}

Bao, J., Gysen, B.L.J. and Lomonova, E.A. (2018) "Hybrid analytical modeling of saturated linear and rotary electrical machines: Integration of Fourier modeling and magnetic equivalent circuits," IEEE Trans. Magn, vol. 54, no. 11, DOI: 10.1109/TMAG.2018.2837896. 
Ben-Yahia, M., Boughrara, K., Dubas, F., Roubache L. and Ibtiouen, R. (2018) "Two-dimensional exact subdomain technique of switched reluctance machines with sinusoidal current excitation", Mathematical and Computational Applications MDPI, vol. 23, no. 4, DOI.org/10.3390/mca23040059.

Boughrara, K., Ladghem-Chikouche, B., Ibtiouen, R., Zarko, D. and Touhami, O. (2009) “Analytical Model of Slotted Air-Gap Surface Mounted Permanent-Magnet Synchronous Motor With Magnet Bars Magnetized in the Shifting Direction," IEEE Trans. Magn, vol.45, no. 2, DOI: 10.1109/TMAG.2008.2008751.

Boughrara, K., Lubin T. and Ibtiouen, R. (2013) "General Subdomain Model for Predicting Magnetic Field in Internal and External Rotor Multiphase Flux-Switching Machines Topologies," IEEE Trans. Magn, vol. 49, no. 10, DOI: 10.1109/TMAG.2013.2260827.

Demenko, A. and Sykulski, J. K. (2016), “Analogies Between Finite-Difference and Finite-Element Methods for Scalar and Vector Potential Formulations in Magnetic Field Calculations," IEEE Trans. Magn, vol. 52, no. 6, DOI: 10.1109/TMAG.2016.2521345.

Djelloul-Khedda, Z., Boughrara, K., Dubas, F. and Ibtiouen, R. (2017) "Nonlinear analytical prediction of magnetic field and electromagnetic performances in switched reluctance machines," IEEE Trans. Magn., vol. 53, no. 7, DOI: 10.1109/TMAG.2017.2679686.

Djelloul-Khedda, Z., Boughrara, K., Dubas, F. Kechroud, A. and Souleyman, B. (2018) "Semi-analytical magnetic field predicting in many structures of permanent-magnet synchronous machines considering the iron permeability," IEEE Trans. Magn, vol. 54, no. 7, DOI: 10.1109/TMAG.2018.2824278.

Dubas, F. and Espanet, C. (2009) "Analytical solution of the magnetic field in permanent-magnet motors taking into account slotting effect: No-load vector potential and flux density calculation," IEEE Trans. Magn, vol. 45, no. 5, DOI: 10.1109/TMAG.2009.2013245.

Dubas, F. and Boughrara, K. (2017a) "New scientific contribution on the 2-D subdomain technique in Cartesian coordinates: Taking into account of iron parts," Math. Comput. Appl., vol. 22, no. 1, DOI: $10.3390 / \mathrm{mca} 22010017$.

Dubas, F. and Boughrara, K. (2017b) "New scientific contribution on the 2-D subdomain technique in polar coordinates: Taking into account of iron parts," Math. Comput. Appl., vol. 22, no. 42, DOI:10.3390/mca22040042.

Faiz, J., Hassanzadeh, M. and Kiyoumarsi, A., (2019) "Analytical calculation of magnetic field in surfacemounted permanent-magnet machines with air-gap eccentricity," COMPEL - Int. J. Comput. Math. Electr. Electron. Eng., vol. 38, no. 2, DOI.org/10.1108/COMPEL-07-2018-0284.

Hanic, A., Zarko D. and Hanic, Z. (2016) "A Novel Method for No-Load Magnetic Field Analysis of Saturated Surface Permanent-Magnet Machines Using Conformal Mapping and Magnetic Equivalent Circuits," IEEE Trans. Eng. Conv, vol. 31, no. 2, DOI: 10.1109/TEC.2015.2507704.

Hanic, A., Zarko, D., Kuhinek D. and Hanic, Z. (2018) “On-Load Analysis of Saturated Surface Permanent Magnet Machines Using Conformal Mapping and Magnetic Equivalent Circuits," IEEE Trans. Energy Convers, vol. 33, no. 3, DOI: 10.1109/TEC.2017.2789322.

Ladghem Chikouche, B. and Ibtiouen R. (2020), “Analytical approach for spoke-type permanent magnet machine including finite permeability of iron core," COMPEL - Int. J. Comput. Math. Electr. Electron. Eng., vol. 39, no. 2, DOI.org/10.1108/COMPEL-04-2019-0143.

Laoubi, Y., Dhifli, M., Verez, G., Amara, Y. and Barakat, G. (2015) "Open circuit performance analysis of a permanent magnet linear machine using a new hybrid analytical model," IEEE Trans. Energy Convers, vol. 51, no. 3, DOI: 10.1109/TMAG.2014.2361017. 
Liu, Y., Zhang, Z., Geng, W. and Li, J. (2017) “A simplified finite-element model of hybrid excitation synchronous machines with radial/axial flux paths via magnetic equivalent circuit," IEEE Trans. Magn, vol. 53, no. 11, DOI: 10.1109/TMAG.2017.2696568.

Lubin, T., Mezani, S. and Rezzoug, A. (2010) "Exact Analytical Method for Magnetic Field Computation in the Air Gap of Cylindrical Electrical Machines Considering Slotting Effects," IEEE Trans. Magn, vol. 46, no. 4, DOI: 10.1109/TMAG.2009.2036257.

Matthew N., Sadiku, O. (2011) "Numerical Techniques in Electromagnetics (2 ${ }^{\text {nd }}$ ed.)," CRC Press LLC.

Nedjar, B., Vido, L., Hlioui, S., Amara, Y. and Gabsi, M. (2012) "Hybrid coupling: Magnetic equivalent circuit coupled to finite element analysis for PMSM electromagnetic modeling," in Proc. ISIE, pp. 858-862, Hangzhou, China, 28-31, DOI: 10.1109/ISIE.2012.6237201.

Niu, S., Chen, N., Ho, S. L. and Fu, W. N., (2012a), "Design Optimization of Magnetic Gears Using Mesh Adjustable Finite-Element Algorithm for Improved Torque," IEEE Trans. Magn, vol. 48, no. 11, DOI: 10.1109/TMAG.2012.2201920.

Niu, S., Ho, S. L., Fu, W. N. and Zhu, J. (2012b) “A Convenient Mesh Rotation Method of Finite Element Analysis Using Sub-Matrix Transformation Approach," IEEE Trans. Magn, vol. 48, no. 2, DOI: 10.1109/TMAG.2011.2173913.

Ouagued, S., Amara, Y. and Barakat, G. (2016a) "Cogging Force Analysis of Linear Permanent Magnet Machines Using a Hybrid Analytical Model," IEEE Trans. Magn, vol. 52, no. 7, DOI: 10.1109/TMAG.2016.2521825.

Ouagued, S., Amara, Y. and Barakat, G. (2016b) "Comparison of hybrid analytical modelling and reluctance network modelling for pre-design purposes," Mathematics and Computers in Simulation, vol. 130, DOI: 10.1016/j.matcom.2016.05.001.

Philips, D.A. (1992) "Coupling finite elements and magnetic networks in magnetostatics," Int. J. for Numerical Methods in Engineering, vol. 35, no.10, DOI: 10.1002/nme.1620351005.

Roubache, L., Boughrara, K., Dubas F. and Ibtiouen, R. (2018) "New subdomain technique for electromagnetic performances calculation in radial-flux electrical machines considering finite softmagnetic material permeability," IEEE Trans. Magn, vol. 54, no. 4, DOI: 10.1109/TMAG.2017.2785254.

Roubache, L., Boughrara, K., Dubas, F., and Ibtiouen, R. (2019) "Elementary subdomain technique for magnetic field calculation in rotating electrical machines with local saturation effect," COMPEL Int. J. Comput. Math. Electr. Electron. Eng., vol. 38, no. 1, DOI: 10.1108/COMPEL-11-2017-0481.

Sprangers, R.L.J., Paulides, J.J.H., Gysen, B.L.J., Waarma, J. and Lomonova, E.A. (2015) "Semianalytical framework for synchronous reluctance motor analysis including finite soft-magnetic material permeability," IEEE Trans. Magn., vol. 51, no. 11, DOI: 10.1109/TMAG.2015.2442419.

Sprangers, R.L.J., Paulides, J.J.H., Gysen, B.L.J. and Lomonova, E.A. (2016) "Magnetic saturation in semi-analytical harmonic modeling for electric machine analysis," IEEE Trans. Magn., vol. 52, no. 2, DOI: 10.1109/TMAG.2015.2480708.

Toudji, M., Parent, G., Duchesne, S. and Dular, P. (2017), "Determination of Winding Lumped Parameter Equivalent Circuit by Means of Finite Element Method," IEEE Trans. Magn, vol. 53, no. 6, DOI: 10.1109/TMAG.2017.2671423.

Wu, L., Yin, H., Wang D. and Fang, Y. (2019) “A Nonlinear Subdomain and Magnetic Circuit Hybrid Model for Open-Circuit Field Prediction in Surface-Mounted PM Machines," IEEE Trans Energy Convers., vol. 34, no. 3, DOI: 10.1109/TEC.2019.2918348.

Wu, L., Yin, H., Wang, D. and Fang, Y. (2020) "On-load field prediction in SPM machines by a 
subdomain and magnetic circuit hybrid model," IEEE Trans Ind. Elec., vol. 67, no. 9, Sep. 2020, DOI: 10.1109/TIE.2019.2942561.

Zarko, D., Ban D., and Lipo, T. A. (2006) "Analytical calculation of magnetic field distribution in the slotted air gap of a surface permanent-magnet motor using complex relative air-gap permeance", IEEE Trans. Magn., vol. 42, no. 7, DOI: 10.1109/TMAG.2006.874594.

\section{APPENDIX A}

Radial magnetization expressions in (5) are defined by:

- for the X-component:

$$
M r_{x s n}=M r_{x c n}=0
$$

- for the y-component:

$$
\begin{aligned}
& M r_{y s n}=m_{r n} \cdot \frac{B_{r m}}{\mu_{o}} \cdot \sin \left(\frac{n \pi}{2}\right) \cdot \sin \left(K_{n} \tau\right) \\
& M r_{y c n}=m_{r n} \cdot \frac{B_{r m}}{\mu_{o}} \cdot \sin \left(\frac{n \pi}{2}\right) \cdot \cos \left(K_{n} \tau\right)
\end{aligned}
$$

where

$$
m_{r n}=\frac{4}{n \pi} \cdot \sin \left(\frac{n \pi \xi}{2}\right)
$$

with $B_{r m}$ is the remanent flux density of PMs, $\tau$ is the rotor position, and $\xi$ is the PM pole-arc to polepitch ratio.

\section{APPENDIX B}

From (23), we have:

$$
\begin{aligned}
& \frac{K_{n}}{\mu_{0}} \cdot\left(C_{3 n}^{I} \cdot e^{K_{n} y_{1}}-C_{4 n}^{I} \cdot e^{-K_{n} y_{1}}\right)=\frac{2}{\tau_{p}} \cdot \int_{0}^{\tau_{p}} H_{x}^{V I I}\left(x, y_{1}\right) \cdot \sin \left(K_{n} x\right) d x \\
& \frac{K_{n}}{\mu_{0}} \cdot\left(C_{5 n}^{I} \cdot e^{K_{n} y_{1}}-C_{6 n}^{I} \cdot e^{-K_{n} y_{1}}\right)=\frac{2}{\tau_{p}} \cdot \int_{0}^{\tau_{p}} H_{x}^{V I I}\left(x, y_{1}\right) \cdot \cos \left(K_{n} x\right) d x
\end{aligned}
$$

where the Fourier constants of (24) can be written as:

$$
h_{x c v}^{V I I}=\frac{2}{\tau_{p}} \cdot \int_{x_{s, j}} \cos \left(K_{n} x\right) d x
$$

From (25), we have:

$$
\begin{aligned}
& C_{3 n}^{I} \cdot e^{K_{n} y_{2}}+C_{4 n}^{I} \cdot e^{-K_{n} y_{2}}+\Gamma_{s}=C_{3 n}^{I I} \cdot e^{K_{n} y_{2}}+C_{4 n}^{I I} \cdot e^{-K_{n} y_{2}} \\
& C_{5 n}^{I} \cdot e^{K_{n} y_{2}}+C_{6 n}^{I} \cdot e^{-K_{n} y_{2}}+\Gamma_{c}=C_{5 n}^{I I} \cdot e^{K_{n} y_{2}}+C_{6 n}^{I I} \cdot e^{-K_{n} y_{2}}
\end{aligned}
$$


From (26), we have:

$$
\begin{aligned}
& C_{3 n}^{I} \cdot e^{K_{n} y_{2}}-C_{4 n}^{I} \cdot e^{-K_{n} y_{2}}=C_{3 n}^{I I} \cdot e^{K_{n} y_{2}}-C_{4 n}^{I I} \cdot e^{-K_{n} y_{2}} \\
& C_{5 n}^{I} \cdot e^{K_{n} y_{2}}-C_{6 n}^{I} \cdot e^{-K_{n} y_{2}}=C_{5 n}^{I I} \cdot e^{K_{n} y_{2}}-C_{6 n}^{I I} \cdot e^{-K_{n} y_{2}}
\end{aligned}
$$

Development of (28) gives:

$$
\begin{gathered}
C_{s 1}^{V}+C_{s 2}^{V} \cdot y_{3}-\frac{\mu_{o}}{2} \cdot J_{z s} \cdot y_{3}^{2}=\frac{1}{w_{s}} \cdot \int_{\alpha_{s}-\frac{w_{s}}{2}}^{\alpha_{s}+\frac{w_{s}}{2}} A_{z}^{I I}\left(x, y_{3}\right) d x \\
C_{s 3 m}^{V} \cdot e^{\beta_{m}^{V} y_{3}}+C_{s 4 m}^{V} \cdot e^{-\beta_{m}^{V} y_{3}}=\frac{2}{w_{s}} \cdot \int_{\alpha_{s}-\frac{w_{s}}{2}}^{\alpha_{s}+\frac{w_{s}}{2}} A_{z}^{I I}\left(x, y_{3}\right) \cdot \cos \left[\beta_{m}^{V} \cdot\left(x-\alpha_{s}+\frac{w_{s}}{2}\right)\right] d x
\end{gathered}
$$

From (29), we have:

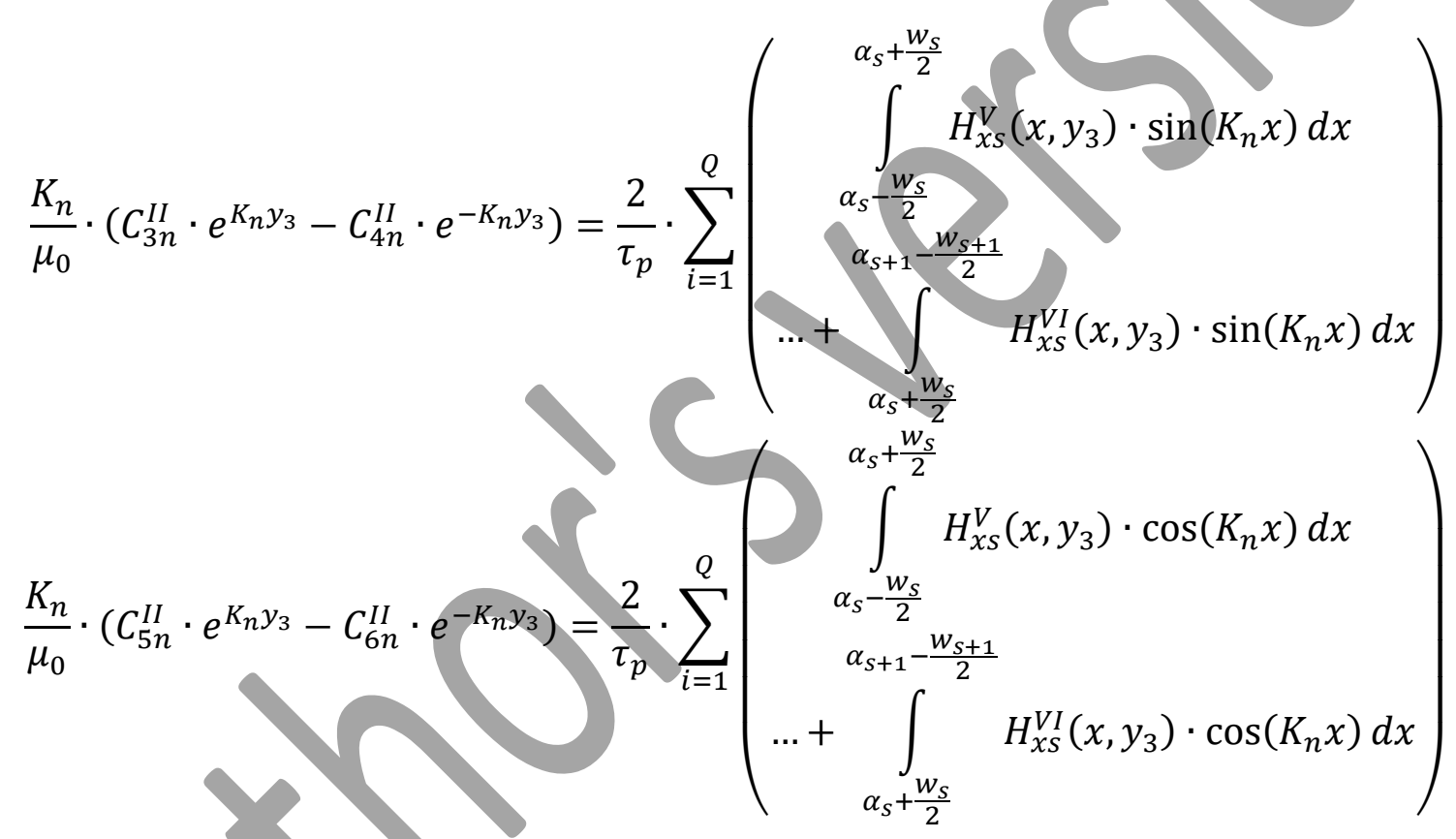

Development of (32) gives:

$$
\begin{gathered}
C_{s 1}^{V}+C_{s 2}^{V} \cdot y_{4}-\frac{\mu_{o}}{2} \cdot J_{z s} \cdot y_{4}^{2}=\frac{1}{w_{s}} \cdot \int_{\alpha_{s}-\frac{w_{s}}{2}}^{\alpha_{s}+\frac{w_{s}}{2}} A_{z}^{I I I}\left(x, y_{4}\right) d x \\
C_{s 3 m}^{V} \cdot e^{\beta_{m}^{V} y_{4}}+C_{s 4 m}^{V} \cdot e^{-\beta_{m}^{V} y_{4}}=\frac{2}{w_{s}} \cdot \int_{\alpha_{s}-\frac{w_{s}}{2}}^{\alpha_{s}+\frac{w_{s}}{2}} A_{z}^{I I I}\left(x, y_{4}\right) \cdot \cos \left[\beta_{m}^{V} \cdot\left(x-\alpha_{s}+\frac{w_{s}}{2}\right)\right] d x
\end{gathered}
$$


From (33), we have:

$$
\begin{aligned}
& \frac{K_{n}}{\mu_{0}} \cdot\left(C_{3 n}^{I I I} \cdot e^{K_{n} y_{4}}-C_{4 n}^{I I I} \cdot e^{-K_{n} y_{4}}\right)=\frac{2}{\tau_{p}} \cdot \sum_{i=1}^{Q}\left(\begin{array}{c}
\int_{\alpha_{s}-\frac{w_{s}}{2}}^{\alpha_{s}+\frac{w_{s}}{2}} H_{x s}^{V}\left(x, y_{4}\right) \cdot \sin \left(K_{n} x\right) d x \\
\ldots+\int_{\alpha_{s}+\frac{w_{s}}{2}}^{\alpha_{s+1}} \\
\ldots+\int_{\alpha_{s}+\frac{w_{s}}{2}}^{V I}\left(x, y_{4}\right) \cdot \sin \left(K_{n} x\right) d x
\end{array}\right)
\end{aligned}
$$

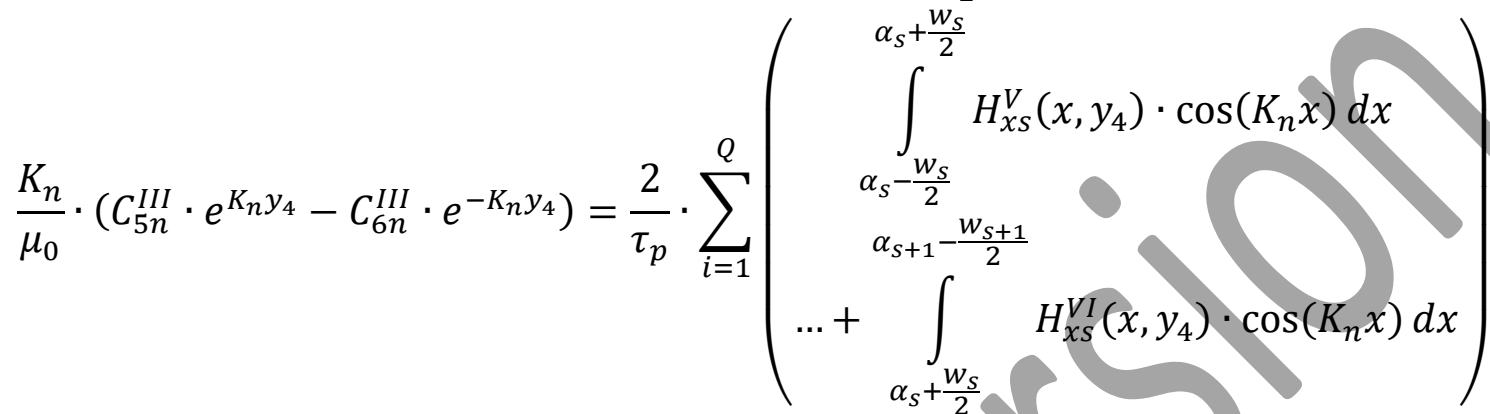

From (35), we have:

$$
\begin{aligned}
& C_{3 n}^{I I I} \cdot e^{K_{n} y_{5}}+C_{4 n}^{I I I} \cdot e^{-K_{n} y_{5}}=C_{3 n}^{I V} \cdot e^{K_{n} y_{5}}+C_{4 n}^{I V} \cdot e^{-K_{n} y_{5}}+\Gamma_{S} \\
& C_{5 n}^{I I I} \cdot e^{K_{n} y_{5}}+C_{6 n}^{I I I} \cdot e^{-K_{n} y_{5}}=C_{5 n}^{I V} \cdot e^{K_{n} y_{5}}+C_{6 n}^{I V} \cdot e^{-K_{n} y_{5}}+\Gamma_{C}
\end{aligned}
$$

From (36), we have:

$$
\begin{aligned}
& C_{3 n}^{I I I} \cdot e^{K_{n} y_{5}}-C_{4 n}^{I I I} \cdot e^{-K_{n} y_{5}}=C_{3 n}^{I V} \cdot e^{K_{n} y_{5}}-C_{4 n}^{I V} \cdot e^{-K_{n} y_{5}} \\
& C_{5 n}^{I I I} \cdot e^{K_{n} y_{5}}-C_{6 n}^{I I I} \cdot e^{-K_{n} y_{5}}=C_{5 n}^{I V} \cdot e^{K_{n} y_{5}}-C_{6 n}^{I V} \cdot e^{-K_{n} y_{5}}
\end{aligned}
$$

From (38), we have:

$$
\begin{aligned}
& \frac{K_{n}}{\mu_{0}} \cdot\left(C_{3 n}^{I V} \cdot e^{K_{n} y_{6}}-C_{4 n}^{I V} \cdot e^{-K_{n} y_{6}}\right)=\frac{2}{\tau_{p}} \cdot \int_{0}^{\tau_{p}} H_{x}^{V I I I}\left(x, y_{6}\right) \cdot \sin \left(K_{n} x\right) d x \\
& \frac{K_{n}}{\mu_{0}} \cdot\left(C_{5 n}^{I V} \cdot e^{K_{n} y_{6}}-C_{6 n}^{I V} \cdot e^{-K_{n} y_{6}}\right)=\frac{2}{\tau_{p}} \cdot \int_{0}^{\tau_{p}} H_{x i}^{V I I}\left(x, y_{6}\right) \cdot \cos \left(K_{n} x\right) d x
\end{aligned}
$$

Some integral function is defined as:

- $1^{\text {st }}$ integral:

$$
\int_{\alpha_{s}-\frac{w_{s}}{2}}^{\alpha_{s}+\frac{w_{s}}{2}} \sin \left(K_{n} x\right) d x=\frac{2 \cdot \sin \left(\frac{K_{n} w_{s}}{2}\right) \cdot \sin \left(K_{n} \alpha_{s}\right)}{K_{n}}
$$

- $2^{\text {nd }}$ integral:

$$
\int_{\alpha_{s}-\frac{w_{s}}{2}}^{\alpha_{s}+\frac{w_{s}}{2}} \cos \left(K_{n} x\right) d x=\frac{2 \cdot \sin \left(\frac{K_{n} w_{s}}{2}\right) \cdot \cos \left(K_{n} \alpha_{s}\right)}{K_{n}}
$$

- $3^{\text {rd }}$ integral: 
COMPEL: The International Journal for Computation and Mathematics in Electrical and Electronic Engineering DOI: 10.1108/COMPEL-02-2021-0039

$$
\int_{\alpha_{s}-\frac{w_{s}}{2}}^{\alpha_{s}+\frac{w_{s}}{2}} \sin \left(K_{n} x\right) \cdot \cos \left[\beta_{m}^{V} \cdot\left(x-\alpha_{s}+\frac{w_{s}}{2}\right)\right] d x=
$$

if $\beta_{m}^{V} \neq K_{n}$

$$
\frac{K_{n}{ }^{2}}{\left(\beta_{m}^{V}\right)^{2}-K_{n}^{2}} \cdot\left\{\cos \left[K_{n} \cdot\left(\frac{w_{s}}{2}+\alpha_{s}\right)\right](-1)^{m}-\cos \left[K_{n}\left(\frac{w_{s}}{2}-\alpha_{s}\right)\right]\right\}
$$

if $\beta_{m}^{V}=K_{n}$

$$
\frac{2 m \pi \cdot \sin \left(K_{n} \alpha_{s}-\frac{m \pi}{2}\right)}{4 K_{n}}
$$

- $4^{\text {th }}$ integral:

$$
\int_{\alpha_{s}-\frac{w_{s}}{2}}^{\alpha_{s}+\frac{w_{s}}{2}} \cos \left(K_{n} x\right) \cdot \cos \left[\beta_{m}^{V} \cdot\left(x-\alpha_{s}+\frac{w_{s}}{2}\right)\right] d x=
$$

if $\beta_{m}^{V} \neq K_{n}$

$$
-\frac{K_{n}^{2}}{\left(\beta_{m}^{V}\right)^{2}-K_{n}^{2}} \cdot\left\{\sin \left[K_{n} \cdot\left(\frac{w_{s}}{2}+\alpha_{s}\right)\right](-1)^{m}+\sin \left[K_{n}\left(\frac{w_{s}}{2}-\alpha_{s}\right)\right]\right\}
$$

if $\beta_{m}^{V}=K_{n}$

$$
\frac{2 m \pi \cdot \cos \left(K_{n} \alpha_{s}-\frac{m \pi}{2}\right)}{4 K_{n}}
$$

- $5^{\text {th }}$ integral:

$$
\frac{\int_{\alpha_{s}-\frac{w_{s}}{2}}^{\alpha_{s}+\frac{w_{s}}{2}} \sin \left(K_{n} x\right) \cdot \sinh \left[\lambda \cdot\left(x-\alpha_{s} \pm \frac{w_{s}}{2}\right)\right] d x=}{2 \cdot\left(\lambda^{2}+K_{n}^{2}\right)} \cdot\left(\begin{array}{c}
-2 K_{n} \cdot \sinh \left(\lambda w_{s}\right) \cdot \cos \left[K_{n} \cdot\left(\alpha_{s}+\frac{w_{s}}{2}\right)\right] \\
\ldots \pm 2 \lambda \cdot \cosh \left(\lambda w_{s}\right) \cdot \sin \left[K_{n} \cdot\left(\alpha_{s}+\frac{w_{s}}{2}\right)\right] \\
\ldots \mp 2 \lambda \cdot \sin \left[K_{n} \cdot\left(\alpha_{s} \mp \frac{w_{s}}{2}\right)\right]
\end{array}\right)
$$

- $6^{\text {th }}$ integral:

$$
\int_{\alpha_{s}-\frac{w_{s}}{2}}^{\alpha_{s}+\frac{w_{s}}{2}} \cos \left(K_{n} x\right) \cdot \sinh \left[\lambda \cdot\left(x-\alpha_{s} \pm \frac{w_{s}}{2}\right)\right] d x=
$$


COMPEL: The International Journal for Computation and Mathematics in Electrical and Electronic Engineering DOI: 10.1108/COMPEL-02-2021-0039

$$
\frac{1}{2 \cdot\left(\lambda^{2}+K_{n}^{2}\right)} \cdot\left(\begin{array}{c}
\mp 2 \lambda \cdot \cosh \left(\lambda w_{s}\right) \cdot \cos \cdot\left[K_{n} \cdot\left(\alpha_{s} \pm \frac{w_{s}}{2}\right)\right] \\
\ldots+2 K_{n} \cdot \sinh \left(\lambda w_{s}\right) \cdot \sin \left[K_{n} \cdot\left(\alpha_{s} \pm \frac{w_{s}}{2}\right)\right] \\
\ldots \mp 2 \lambda \cdot \cos \left[K_{n} \cdot\left(\alpha_{s} \mp \frac{w_{s}}{2}\right)\right]
\end{array}\right)
$$

- $7^{\text {th }}$ integral:

$$
\int_{y_{3}}^{y_{4}} \sin \left[\lambda \cdot\left(y-y_{3}\right)\right] d y=-\frac{-1+\cos \left[\lambda \cdot\left(y_{4}-y_{3}\right)\right]}{\lambda}
$$

- $8^{\text {th }}$ integral:

$$
\int_{y_{3}}^{y_{4}} y \cdot \sin \left[\lambda \cdot\left(y-y_{3}\right)\right] d y=-\frac{\lambda y_{4} \cdot \cos \left[\lambda \cdot\left(y_{4}-y_{3}\right)\right]-\sin \left[\lambda \cdot\left(y_{4}-y_{3}\right)\right]-\lambda y_{3}}{\lambda}
$$

- $9^{\text {th }}$ integral:

$$
\int_{y_{3}}^{y_{4}} y^{2} \cdot \sin \left[\lambda\left(y-y_{3}\right)\right] d y=\frac{\left(-\lambda^{2} y_{4}^{2}+2\right) \cdot \cos \left[\lambda \cdot\left(y_{4}-y_{3}\right)\right]+\lambda^{2} y_{4}^{2}}{\ldots+\frac{2 \lambda y_{4} \cdot \sin \left[\lambda \cdot\left(y_{4}-y_{3}\right)\right]-2}{\lambda^{3}}}
$$

